Este libro forma parte del acervo de la Biblioteca Jurídica Virtual del Instituto de Investigaciones Jurídicas de la UNAM

\title{
"SOY EL MESSIAS PERO NO HAGO MILAGROS": RELIGIÓN Y POLÍTICA EN AMÉRICA LATINA EN CONTEXTO DE PANDEMIA
}

\author{
Pauline CAPDEVIELLE
}

\begin{abstract}
SUMARIO: I. Introducción. II. Laicidad, secularización y populismo religioso en América Latina. III. Religión, discursos y cultura política en América Latina en tiempos de COVID-19. IV. Bioética, ciencia y cultura laica en América Latina en contexto de pandemia. V. Conclusiones. VI. Bibliografia.
\end{abstract}

\section{INTRODUCGIÓN}

América Latina registró su primer caso de COVID-19 en São Paulo, Brasil, el 26 de febrero de 2020. Desde entonces se ha convertido en la región con más casos confirmados, representando un cuarto de los casos a nivel mundial $^{1}$ y contabilizando, a inicios de agosto, aproximadamente 200,000 muertos $^{2}$. Para contener la pandemia, los gobiernos nacionales han implementado diversas medidas: cuarentenas (con grados variables de obligatoriedad), organización de campañas de prevención, uso obligatorio de cubrebocas, etc. Sin embargo, de forma paralela a la adopción de medidas respaldadas por la evidencia científica, llama la atención la activación de una narrativa de índole religiosa por parte de muchos dirigentes de la región, que hace énfasis en las creencias y prácticas religiosas (o espirituales) como un factor de protección y sanación de la enfermedad causada por el virus SARS-CoV-2.

Este trabajo se enfoca en las relaciones entre política y religión en América Latina en las primeras semanas de la pandemia de COVID-19, entre

\footnotetext{
1 Horwitz, Luisa, Nagovitch, Paola, Sonneland, Holly K. y Zissis, Carin, "The coronavirus in Latin America", America Society Council of the Americas, 12 de agosto de 2020, disponible en: https://wrereas-coa.org/articles/coronavirus-latin-america.

2 Guerrero, Kay, "América Latina y el Caribe superan las 200.000 muertes por covid-19", CNN Español, 2 de agosto de 2020, consultado el 4 de octubre de 2020, disponible en: https://cnnespanol.cnn.com/2020/08/02/america-latina-y-el-caribe-superan-las-200-000-muertes -por-covid-19/.
} 
Este libro forma parte del acervo de la Biblioteca Jurídica Virtual del Instituto de Investigaciones Jurídicas de la UNAM

los meses de marzo y agosto de 2020. Su objetivo consiste en describir y arrojar algunas pistas de análisis en torno a la activación de un discurso religioso en la esfera política, en particular, por parte de los mandatarios y respecto a la gestión de la crisis sanitaria. Se hará énfasis en cómo lo religioso ha permeado el discurso político de los dirigentes, en una región que se caracteriza a la vez por el avance de un consenso en torno al carácter laico (o secular) del poder político, y por la persistencia de lo religioso como elemento de legitimación de los Estados y de los gobiernos, en una región desigualmente secularizada. Así las cosas, el trabajo buscará responder a las siguientes preguntas: ¿cómo interpretar la utilización de la narrativa religiosa como fenómeno común a muchos países de la región en las primeras semanas de la pandemia?, ¿cuáles son los riegos asociados con la movilización de este tipo de discurso? La hipótesis que guía nuestro análisis es que la COVID-19 no constituye, per se, el disparador del entusiasmo religioso de los dirigentes, sino que la exacerbación del discurso religioso surge en el marco de condiciones estructurales preexistentes, que se agudizan en el contexto de la crisis sanitaria, especialmente, ante la respuesta endeble de las instituciones estatales.

El trabajo se divide en tres apartados. En el primero, se esboza el contexto general de las relaciones entre la política y la religión en América Latina, a partir de algunas herramientas conceptuales que nos parecen útiles para plantear las coordinadas de la problemática, en particular, el desajuste entre laicidad y secularización en el marco de la presencia histórica del populismo religioso en la región. En un segundo momento, el trabajo se enfoca a la recopilación y análisis de algunas de las declaraciones de los líderes regionales que nos parecen más ilustrativas de un reblandecimiento de la laicidad en la contingencia sanitaria, y que buscan subsanar respuestas institucionales insuficientes. $\mathrm{Al}$ respecto, se hace una distinción entre los discursos orientados a pedir una intervención divina para frenar los contagios y las muertes, y una tendencia hacia la mesianización de los liderazgos, especialmente, en los casos mexicanos y brasileños. El tercer acápite busca ofrecer una reflexión en torno a la necesidad de consolidar un pensamiento bioético y una cultura laica en la región, especialmente en un contexto de crisis sanitaria.

\section{LAICIDAD, SECULARIZACIÓN Y POPULISMO RELIGIOSO EN AMÉRICA LATINA}

La imbricación de lo religioso y lo político no es un fenómeno novedoso en América Latina. Se inscribe en un marco histórico de legitimación religiosa 
Este libro forma parte del acervo de la Biblioteca Jurídica Virtual del Instituto de Investigaciones Jurídicas de la UNAM

del poder político en la región, que remonta por lo menos al proceso de colonización. Asimismo, la unión entre política y religión constituye un rasgo de origen de los Estados en la región, los cuales, en varios casos, no lograron del todo romper esta tradición en los procesos de consolidación de los Estados modernos, a pesar de las luchas políticas entre Estados e Iglesia en los siglos XIX y XX. ${ }^{3}$ La región se presenta como un escenario complejo, en el cual cada país transitó por sus propias experiencias en materia de relación entre el Estado, la religión y la sociedad, dando lugar a un amplio espectro de situaciones y manifestaciones. ${ }^{4}$ A pesar de esta diversidad, es posible trazar continuidades (o contrastes) entre ellos, especialmente, al movilizarse los conceptos de laicidad, secularización, cultura política y populismo religioso.

La laicidad, de acuerdo con Roberto Blancarte, puede definirse como "un régimen social de convivencia, cuyas instituciones están legitimadas principalmente por la soberanía popular y (ya no) por elementos religiosos". ${ }^{5}$ Esta definición resulta útil para nuestro análisis, puesto que se centra en la cuestión de la legitimidad del poder político, esto es, el vínculo de obediencia entre el Estado y los individuos. El Estado laico hace énfasis en la cuestión de la ciudadanía como espacio universal, relegando la cuestión de las creencias religiosas al ámbito privado de los individuos. Como horizonte normativo, busca, mediante la autonomía entre el Estado y las iglesias, asegurar las libertades fundamentales de las personas y la toma de decisiones colectivas basada en la deliberación y el debate, y no a partir de sustratos religiosos. Al respecto, cabe mencionar que no existe un solo modelo de laicidad, sino que cada Estado que se ostenta como laico o secular tiene sus propias configuraciones de relación entre el Estado y las iglesias, construidas con base en los conflictos y consensos que surgieron a lo largo de su historia particular. Sin embargo, ya sea en sus versiones liberales o republicanas, la laicidad implica la exclusión de todo contenido religioso de las instituciones del Estado y de los discursos políticos, ${ }^{6}$ lo anterior, para garantizar las con-

3 Sobre este tema y su complejidad, véase Bohoslavsky, Ernesto, Laicidad y América Latina, México, UNAM, Instituto de Investigaciones Jurídicas, 2013, Colección de Cuadernos "Jorge Carpizo. Para Entender y Pensar la Laicidad", disponible en: http://catedra-laicidad.unam. $m x /$ detalle-jorge-carpizo/43/11-Laicidad-y-América-Latina.

4 Blancarte, Roberto, "Definir la laicidad (desde una perspectiva mexicana)", Revista Internacional de Filosofia Política, s. 1. i., núm. 24, 2004, pp. 15-28, disponible en: http://biblioteca. clacso.edu.ar/clacso/gt/20121213010651/Crucesinterseccionesconflictos.pdf, p. 12.

5 Blancarte, Roberto, "Definir la laicidad..., op. cit.

6 Rivera, Faviola, Laicidad y liberalismo, México, Instituto de Investigaciones Jurídicas de la UNAM, 2013, Colección de Cuadernos "Jorge Carpizo. Para Entender y Pensar la Laicidad, p. 8. 
Este libro forma parte del acervo de la Biblioteca Jurídica Virtual del Instituto de Investigaciones Jurídicas de la UNAM

diciones de pluralismo que han de guiar la deliberación democrática y la plena vigencia de los derechos humanos. ${ }^{7}$

A diferencia del principio de laicidad como un modelo normativo que se mueve entre lo político y lo jurídico, la secularización atañe a los procesos sociales y culturales de la pérdida de centralidad de la religión en la sociedad. Utilizado en los años sesenta y setenta del siglo pasado como paradigma de la desaparición progresiva y ineluctable de lo religioso en contextos de modernidad, ha sido objeto de reformulaciones que siguen siendo útiles para entender la recomposición del fenómeno religioso en la actualidad. Asimismo, para José Casanova, la secularización puede ser entendida desde diferentes aristas, como declive de las creencias, privatización de la religión y separación y autonomización de las diferentes esferas sociales (política, ciencia, religión, etcétera). ${ }^{8}$ Esta distinción entre diferentes significados permite mostrar las diferentes combinaciones que pueden coexistir en la práctica, poniendo de relieve la complejidad del fenómeno religioso en las sociedades, el cual, lejos de haber desaparecido, se ha adaptado a las múltiples formas que la modernidad ostenta en la región.

Felipe Gaytán insiste en la relevancia de la categoría de cultura política para construir un puente entre la laicidad, entendida como las configuraciones político-jurídicas entre poder político y religioso, y la secularización como conjunto de procesos sociales y culturales en torno a la religión. ${ }^{9} \mathrm{El}$ concepto de cultura política busca estudiar los patrones, orientaciones y valores que caracterizan determinados sistemas políticos. De acuerdo con Sidney Verba, se puede definir como un "sistema de creencias empíricas, símbolos expresivos y valores, que definen la situación dentro de la cual se da la acción política. Proporciona la orientación subjetiva de la política". ${ }^{10}$ Asimismo, dicho concepto podría fungir como llave de comprensión del desfase que puede existir entre el carácter laico de un Estado, y la utilización de una narrativa religiosa por parte de los dirigentes políticos, en el marco de sociedades desigual y parcialmente secularizadas.

$\mathrm{Al}$ respecto, aunque un gran número de Estados latinoamericanos han eliminado las disposiciones relativas a una Iglesia de Estado y han expresado

7 Salazar Ugarte, Pedro, La laicidad: antídoto contra la discriminación, México, Conapred, Cuadernos de la igualdad núm. 8, 2007, pp. 39 y ss.

8 Casanova, José, "Reconsiderar la Secularización: Una perspectiva comparada mundial”, Revista Académica de Relaciones Internacionales, México, UAM-AEDRI, núm. 7, 2007, disponible en: https://cetr.net/files/1299066933_casanova_reconsiderar_la.pdf.

9 Gaytán Alcalá, Felipe, La inmaculada política de los salvos. Moraly religión en la agenda política de los partidos políticos, México, UNAM, Instituto de Investigaciones Jurídicas (en prensa).

10 Verba, Sidney, "El estudio de la ciencia política desde la cultura política", Revista de Estudios Políticos, México, núm. 138, 1964, p. 5. 
Este libro forma parte del acervo de la Biblioteca Jurídica Virtual del Instituto de Investigaciones Jurídicas de la UNAM

en sus constituciones referencias explícitas a la laicidad (o conceptos afines), siguen siendo numerosas las invocaciones religiosas en los preámbulos ${ }^{11}{ }^{\mathrm{en}}$ turbiando el sentido y los alcances del principio de laicidad. Algunos especialistas han llamado la atención en el surgimiento, en América Latina, de Estados pluri-religiosos o pluri-confesionales, esto es, configuraciones estatales que, lejos de organizar una separación nítida entre la esfera pública y religiosa, extienden una serie de beneficios a determinado número de denominaciones religiosas, impulsando modelos de colaboración entre ellos y el Estado, y privilegiando, de esta manera, una visión religiosa del mundo por encima de una secular. ${ }^{12} \mathrm{Al}$ respecto, Felipe Gaytán apunta que este enfoque, lejos de garantizar un mayor pluralismo en la deliberación pública, genera un espacio político en el cual la discusión ciudadana es desplazada en beneficio de las instituciones religiosas, las cuales invocan legitimidades externas a lo político y alejadas del uso de la razón pública. ${ }^{13}$ Cabe mencionar que este fenómeno se inscribe en un proceso de diversificación religiosa de América Latina en el cual las iglesias evangélicas lograron tomar mayor protagonismo, y en varios casos fueron exitosas en acercarse a las esferas de poder e influir en los discursos, valores y comportamientos políticos.

Otra categoría de análisis sin duda fundamental para entender el recurso a lo religioso en la esfera política es el de populismo. Como señala Shmuel Eisenstadt, el populismo es un elemento imprescindible para entender los procesos de construcción de la esfera pública en América Latina, en particular, de las identidades claves a nivel nacional. ${ }^{14}$ Se caracteriza, a grandes rasgos, por la apelación al pueblo como unidad orgánica, una concepción maniquea de la política y la relación inmediata entre el líder y el pueblo vs. la élite. ${ }^{15}$

11 Para un panorama completo de las previsiones legales en materia de laicidad en América Latina, véase la Plataforma "Mira que te miro", disponible en: https://miraquetemiro.org/.

12 Véase, sobre este tema, Huaco, Marco, "Perú hacia un modelo pluriconfesional: el caso de la nueva ley de libertad religiosa", Revista del Centro de Investigación, México, Universidad La Salle, vol. 9, núm. 36, julio-diciembre, 2011, pp. 93-109; Esquivel, Juan, "Laicidades relativas, avatares de la relación Estado Iglesia en Brasil”, en Blancarte, Roberto (ed.), Los retos de la laicidad y la secularización en el mundo contemporáneo, México, El Colegio de México, 2008.

13 Gaytán Alcalá, Felipe, Manuales de redentores: Laicidad y derechos, entre populismo y neojacobinismo, México, UNAM, Instituto de Investigaciones Jurídicas, 2016, p. 8.

14 Eisenstadt, Shmuel N., "América Latina y el problema de las múltiples modernidades", Revista mexicana de ciencias políticas y sociales, México, vol. 58, núm. 218, mayo-agosto, 2013, disponible en: http://wrere.scielo.org.mx/scielo.php.'script=sci_arttextEpid=S0185-19182013000200007.

15 Salmorán Villar, María de Guadalupe, "Populismo: una ideología antidemocrática", Teoria politica, Italia, núm. 7, Annali VII, 2017, pp. 128-154, disponible en: https://journals. openedition.org/tp/533. 
Este libro forma parte del acervo de la Biblioteca Jurídica Virtual del Instituto de Investigaciones Jurídicas de la UNAM

$\mathrm{Al}$ respecto, Esquivel y Malimacci notan que dicho populismo no puede entenderse sin considerar el papel que la religión ha jugado en la religión, puesto que no sería otra cosa que una versión contemporánea del imaginario carismático de tipo católico construido a lo largo de la historia. ${ }^{16}$ De esta manera, estos autores hacen hincapié en la importancia de la utilización de los símbolos religiosos en la discursiva de algunos líderes en América Latina, en particular, los temas del sacrificio, esperanza, recompensa, redención y salvación, aspectos que aparecen con fuerza en algunos de los pronunciamientos de los dirigentes latinoamericanos respecto a la pandemia. En el imaginario populista latinoamericano, la feligresía se confunde con el pueblo vs. el ateísmo de las élites, y en algunos casos, la inmediación del líder asume rasgos mesiánicos, como se verá a continuación. También, el discurso parece adoptar cada vez más los códigos de la cultura evangélica, en una región en la que ahora uno de cada cinco persona pertenece a una iglesia no católica. Asimismo, la idea de un Dios activo en el mundo, las prácticas mágico-religiosas, la continua acción sanadora de Jesús, la intercesión y el milagro como experiencia cotidiana permea cada vez más la cultura política. ${ }^{17}$

Existen, por lo tanto, las condiciones preexistentes a la adopción de un lenguaje religioso por parte de los dirigentes en el contexto de la pandemia. Lejos de generar una ruptura con esta tradición, la crisis exacerba los patrones estructurales prevalecientes de la relación entre gobernantes y gobernados. Al respecto, Paul B. Preciado, en su ensayo "Aprendiendo del virus" ${ }^{18}$ nota que la pandemia actúa a nuestra imagen y semejanza, no hace más que replicar, materializar, intensificar las formas dominantes de gestión de la biopolítica. En otras palabras, el virus no produce una nueva realidad, sino que pone en evidencia los resortes del poder y de la obediencia, las dinámicas sociales y las fragilidades y fracturas de las sociedades. El examen de las narrativas activadas en las primeras semanas de la crisis sanitaria en las primeras semanas de pandemia parece confirmar esta línea de análisis:

\footnotetext{
16 Esquivel, Juan Cruz y Mallimaci, Fortunato, "Políticas y religiones en América Latina y el Caribe: recomposiciones históricas, epistemológicas y conceptuales", Anuario de Historia Regional y de las Fronteras, vol. 23, núm. 2, Bucaramanga, julio-diciembre de 2018, disponible en: $h t t p: / /$ wwre.scielo.org.co/scielo.php?'script=sci_arttextEpid=S0122-20662018000200013.

17 Sobre este tema, véase la obra colectiva Pérez Guadalupe, José Luis y Grundberger, Sebastian (ed.), Evangélicos y Poder en América Latina, Instituto de Estudios Social Cristianos/ Konrad Adenauer Stiftung, 2018, disponible en: https://cpalsocial.org/documentos/926.pdf.

18 Preciado, Paul B., "Aprendiendo del virus", El País, 27 marzo 2020, disponible en: https://elpais.com/elpais/2020/03/27/opinion/1585316952_026489.html, consultado el 16 de agosto de 2020.
} 
Este libro forma parte del acervo de la Biblioteca Jurídica Virtual del Instituto de Investigaciones Jurídicas de la UNAM

la exacerbación de un discurso religioso y populista ante la fragilidad de las instituciones estatales para hacer frente a la crisis sanitaria.

\section{RELIGIÓN, DISGURSOS Y GULTURA POLÍTICA EN AMÉRICA LATINA EN TIEMPOS DE GOVID-19}

El discurso político se entiende como medio de acción y de intervención política. No solamente transmite información, sino que construye y modifica las relaciones de los individuos en el mundo social. Permite hacer hincapié en contexto en el cual surge, y encontrar claves para entender la realidad mediante la expresión de valores, visiones y representaciones. ${ }^{19}$ De acuerdo con van Dijk, el discurso político modifica las formas de pensar la realidad, por lo que debe entenderse desde el concepto de poder y como forma de control social. ${ }^{20}$ Bourdieu lo expresa en los siguientes términos: "si el trabajo político es, en lo esencial, un trabajo sobre las palabras, es que las palabras contribuyen a formar el mundo social". ${ }^{21}$

Respecto a la activación desde el poder político del discurso religioso en contexto de pandemia, puede distinguirse dos fenómenos distintos que guardan relaciones entre sí: por un lado, discursos en los cuales los líderes regionales piden, mediante la promoción de oraciones y ayunos, una intervención divina para frenar la propagación del virus; por el otro, una tendencia a la mesianización de algunos líderes regionales, es decir, una sacralización de sus personas con base en la movilización del imaginario religioso.

\section{El llamado a la intervención divina: entre impotencia y control social}

A finales del mes de abril de 2020, la presidente interina del Estado Plurinacional de Bolivia, Jeanine Áñez, convocó a los bolivianos a observar un día de oración y ayuno en familia, asegurando que "para Dios nada es imposible". ${ }^{22}$ Se organizaron sobrevuelos de bendición religiosa en diferen-

19 Gutiérrez, Silvia, Discursos politicos y argumentación, México, Universidad Autónoma Metropolitana, Unidad Xochimilco, 2006, disponible en: http://web.uchile.cl/facultades/filosofia/ Editorial/libros/discurso_cambio/72Gutie.pdf.

20 Van Dijk, Teun, Sociedad y discurso, Barcelona, Gedisa, 2011.

21 Bourdieu, Pierre, "El discurso es resultado de la reunión entre un habitus lingüístico y el mercado", Libération, 19 de octubre de 1982, disponible en: http://wrwre.periodismo.undav.edu. ar/asignatura_lic/cs215_radio_2/material/que_significa_hablar-pierre_bourdieu.pdf.

22 EFE, "Presidente de Bolivia pide jornada de «ayuno y oración» para vencer pandemia", Milenio, 27 de abril de 2020, disponible en: https://wrere.milenio.com/internacional/ 
Este libro forma parte del acervo de la Biblioteca Jurídica Virtual del Instituto de Investigaciones Jurídicas de la UNAM

tes ciudades del país desde el helicóptero presidencial, a la vez que patrullaron camionetas de la policía portando imágenes religiosas de yeso. ${ }^{23}$ De acuerdo con el artículo 4o. de su constitución, Bolivia es un Estado laico, al ser el Estado independiente de la religión. ${ }^{24}$ Estos hechos generaron una ola de críticas, con el posicionamiento, en las redes sociales, de las etiquetas \#NiAyunoNiOración y \#EstadoLaico. ${ }^{25}$

En Guatemala, el presidente Alejandro Giammattei, ubicado a la derecha conservadora del espectro político, convocó y declaró un "sábado de ayuno y oración nacional" para pedirle a Dios que libere a Guatemala de la COVID-19, cerrando sistemáticamente su espacio informativo sobre la pandemia con la expresión "Qué Dios bendiga a Guatemala". ${ }^{26}$ En el vecino Honduras, el controvertido presidente Juan Orlando Hernández (derecha) llamó a los hondureños, en vivo en la televisión nacional y desde su página de Facebook, a ayunar y rezar durante el "Gran día de oración para la salud y la unidad del pueblo hondureño". ${ }^{27}$ Durante el mes mayo, en El Salvador, el joven y pragmático presidente Nayib Bukele impulsó la publicación, en el Diario Oficial, de un día nacional de oración "Para que Dios sane nuestra tierra y nos permita vencer a la pandemia que está golpeando el mundo entero". Precisó que la participación a dicho evento era de cumplimiento voluntario - "como toda verdadera oración"-, que era legal y con vigencia en todo el territorio nacional. ${ }^{28}$ Ya en marzo había llamado a

latinoamerica/coronavirus-presidenta-bolivia-pide-jornada-ayuno-oracion, consultado el 14 de agosto de 2020.

23 AFP, "Bolivia pide ayuda a Dios para vencer a Covid-19", El Economista, 28 de abril de 2020, disponible en: https://wrere.eleconomista.com.mx/internacionales/Bolivia-pide-apoyo-a-Diospara-vencer-a-Covid-19-20200428-0156.html, consultado el 14 de agosto de 2020.

24 "Artículo 4o. El Estado respeta y garantiza la libertad de religión y de creencias espirituales, de acuerdo con sus cosmovisiones. El Estado es independiente de la religión". Constitucion Política del Estado, disponible en: https://wrere.oas.org/dil/esp/Constitucion_Bolivia.pdf, consultado el 14 de agosto de 2020.

25 AFP, "Bolivia pide ayuda a Dios..., op. cit.

26 López, Esvin, “¿Cómo se hace el ayuno? ¿Qué significa? ¿Cuál es su propósito?, Publinews.gt, 21 de marzo de 2020, disponible en: https://wrwre.publinewes.gt/gt/noticias/2020/03/21/ ayuno-iglesias-guatemala-21-marzo-2020.html, consultado el 21 de agosto de 2020.

27 Orlando Hernández, Juan, “\#EnVivo: Gran Jornada de Oración por la Salud y la Unidad del Pueblo Hondureño. De la mano de Dios, ¡vamos a salir adelante!”, Facebook, 17 de marzo de 2020, disponible en: https://wrerrefacebook.com/124300620957187/videos /199347784683431/, consultado el 21 de agosto de 2020.

28 Europa Press, "El presidente de El Salvador decreta un día nacional de oración en el que pedir ayuda a Dios para vencer al coronavirus", Notimérica, 22 de mayo de 2020, disponible en: https://wrere.notimerica.com/sociedad/noticia-presidente-salvador-decreta-dia-nacional-oracionpedir-ayuda-dios-vencer-coronavirus-20200522200218.html, consultado el 14 de agosto de 2020. 
Este libro forma parte del acervo de la Biblioteca Jurídica Virtual del Instituto de Investigaciones Jurídicas de la UNAM

los creyentes a rezar por el país, explicando saber que el país es laico, pero que "habemos muchos creyentes". ${ }^{29}$

En Nicaragua, la vicepresidenta Rosario Murillo, esposa del mandatario Daniel Ortega, utilizó los canales de comunicación del gobierno para convocar a la población a una serie de eventos masivos titulados "Amor en tiempos del COVID-19", para comunicar sobre los gestos de protección ante la pandemia. Justificó la iniciativa explicando que "Vamos a caminar con la fuerza de la fe y la esperanza en todo el país, en oración permanente y solidaridad con todos los pueblos, familias y hermanos en el mundo afectados por el coronavirus". Las imágenes de las marchas multitudinarias fueron retomadas por los medios de comunicación de la región y del mundo. ${ }^{30}$

En 25 de marzo, en Colombia, el presidente Duque (Partido Nacional, derecha), da inicio a los primeros diecinueve días de cuarentena obligatoria, pidió a cada hogar y a cada colombiano, de acuerdo con sus creencias, llevar al país en sus oraciones o pensamientos, destacando la importancia, para el país, de la Virgen del Rosario de Chiquinquirá y el Sagrado Corazón de Jesús. ${ }^{31}$ Tras una serie de mensajes religiosos publicados por el presidente desde su cuenta personal de Twitter, un ciudadano interpuso un recurso ante las autoridades judiciales contra uno de ello, al considerarlo discriminatorio. El Tribunal Superior de Cali pidió al mandatario "abstenerse de realizar este tipo de alegorías a cultos en particular, desde las redes sociales", señalando que

Para esta corporación el mensaje emitido por el Presidente no cumple con los mínimos de justificación y razonabilidad, por ser un claro discurso en materia religiosa cuya divulgación es prohibida, pues implica el desconocimiento del derecho de libertad de culto, y el deber de neutralidad del Estado, y en consecuencia, es vulneratorio del principio de laicidad del Estado. ${ }^{32}$

29 Elsalvadorgram, "Bukele llama a los «creyentes» a orar por el país: «Pidamos a Dios que nos ayude a afrontar este problema», elsalvadorgram, 15 de marzo de 2020, disponible en: https://elsalvadorgram.com/2020/03/bukele-llama-a-los-creyentes-a-orar-por-el-pais-pidamos-a-diosque-nos-ayude-a-afrontar-este-problema/, consultado el 14 de agosto de 2020.

30 EFE, "El gobierno de Nicaragua desafia al coronavirus con una marcha multitudinaria", Agencia EFE, 15 de marzo de 2020, disponible en: https://wrerrefe.com/efe/espana/sociedad/el-gobierno-de-nicaragua-desafia-al-coronavirus-con-una-marcha-multitudinaria/10004-4196161, consultado el 14 de agosto de 2020.

31 Cantillo, Jorge, "Ivan Duque pidió encomendarse al Sagrado Corazón y a la Virgen de Chiquinquirá durante la cuarentena de Colombia por el coronavirus", Infobae, 25 de marzo de 2020, disponible en: https://wrere.infobae.com/america/colombia/2020/03/25/ivan-duquepidio-encomendarse-al-sagrado-corazon-y-a-la-virgen-de-chiquinquira-durante-la-cuarentena-de-colombiapor-el-coronavirus/, consultado el 15 de agosto de 2020.

32 Infobae, "Iván Duque escribió un tuit sobre la Virgen y la justicia le ordenó borrarlo", Infobae, 27 de julio de 2020, disponible en: https://wrere.infobae.com/america/colom- 
Este libro forma parte del acervo de la Biblioteca Jurídica Virtual del Instituto de Investigaciones Jurídicas de la UNAM

Desde luego, uno de los casos más emblemáticos es el Brasil de Bolsonaro (ultraderecha), tanto por la amplitud de la crisis sanitaria que vive el país, como por la utilización sistemática de la religión en el contexto de la pandemia. El mandatario, famoso por sus declaraciones polémicas, describió en un primer tiempo la enfermedad como una gripezinha (gripita) e incluso como una invención de los medios dominados por la izquierda global. ${ }^{33}$ Aún a falta de evidencia científica, defendió a ultranza la utilización de la hidroxicloroquina como tratamiento eficaz contra la COVID-19, apoyado en ello por sus aliados evangélicos, los cuales han promocionado una receta que mezcla dicho fármaco con semillas de frijol, invocaciones a Jesús y oraciones colectivas. ${ }^{34}$

Incluso en el muy laico Uruguay, el presidente Luis Alberto Lacalle Pou participó a una "Oración interreligiosa por la Patria" en la Catedral de Montevideo, y declaró que, si bien el Estado es laico, no es laicista, por lo que "Todas las iniciativas a favor de la nación y del país son bienvenidas, las religiosas, las laicas, todas". ${ }^{35}$ México, otro referente de Estado laico en la región, no se quedó atrás. El presidente de la República, que se presenta a la vez como el heredero de la tradición juarista y de la doctrina cristiana, presumió en una conferencia matutina durante el mes de marzo, sus escudos protectores: un escapulario del Sagrado Corazón de Jesús, un trébol y un billete de dos dólares. Expresó: "Detente enemigo, que el Corazón de Jesús está conmigo. Pero no hay siquiera enemigos, son adversarios. Yo no tengo enemigos ni quiero tenerlos. El escudo protector es como el detente, es la honestidad, eso es lo que protege: no permitir la corrupción".

En una misma veta, y retomando la crisis sanitaria al servicio de su proyecto de moralización del país, señaló un par de meses después que "estar

bia/2020/07/27/ivan-duque-escribio-un-tuit-sobre-la-virgen-y-la-justicia-le-ordeno-a-borrarlo/, consultado el 14 de agosto de 2020.

33 Redacción, "Bolsonaro da positivo por coronavirus: 8 polémicas frases con las que el presidente de Brasil minimizó el impacto del covid-19 antes de contagiarse", BBC Newes Mundo, 7 julio 2020, disponible en: https://wrere.bbc.com/mundo/noticias-america-latina-53313893, consultado el 10 de agosto de 2020.

34 Arias, Juan, "La receta medieval contra el coronavirus que mezcla a Jesús, cloroquina, semillas milagrosas, ayunos y oraciones", El País, 21 de mayo de 2020, disponible en: https:// elpais.com/opinion/2020-05-21/la-receta-medieval-contra-el-coronavirus-que-mezcla-a-jesus-cloroquina-semillas-milagrosas-ayunos-y-oraciones.html, consultado el 14 de agosto de 2020.

35 Uruguay Presidencia, "Presidente Luis Lacalle participó en la «Oración interreligiosa por la patria» en la Catedral de Montevideo", Uruguay Presidencia, 2 de marzo de 2020, disponible en: https://wrwrepresidencia.gub.uy//comunicacion/comunicacionnoticias/presi dente-lacalle-pou-catedral-montevideo-sturla-oracion-interreligiosa, consultado el 13 de agosto de 2020. 
Este libro forma parte del acervo de la Biblioteca Jurídica Virtual del Instituto de Investigaciones Jurídicas de la UNAM

bien con nuestra conciencia, no mentir, no robar, no traicionar, eso ayuda mucho para que no dé el coronavirus". ${ }^{36}$ Estas declaraciones causaron revuelo en el país, al considerarse incompatibles con el régimen laico e irresponsables en contexto pandémico. ${ }^{37}$

Como lo expresó el tribunal colombiano, las referencias a la religión por parte de los mandatarios parecen en abierta contradicción con el consenso laico constitucional que prevalece en la religión, y que implica una autonomía efectiva entre potestades civil y religiosa, teniendo como consecuencia la exclusión de los sectores de la población que no comparten las posturas religiosas de sus representantes. También, la recopilación de estos ejemplos permite identificar algunos elementos que no dejan de ser significados en el contexto de la pandemia:

i. Llama la atención, en primer lugar, la irrupción de un discurso que se mueve entre magia y religión. Mientras la primera se presenta como un conjunto actos orientados a la consecución de fines determinados y el control sobre la naturaleza, la segunda constituye una rutinización o institucionalización de las creencias y prácticas, en el marco habitual de los oficios cultuales. ${ }^{38}$ Asimismo, la organización de jornadas de oración y ayunos colectivos desbordan del marco institucionalizado de la religión y buscan actuar de manera sobrenatural y instrumentalizar el deseo, algo que aparece con fuerza con la ostensión de grisgrís protectores por parte del presidente mexicano y que rompe claramente con la racionalidad y responsabilidad que ha de ostentar el liderazgo político.

ii. Es difícil no percibir en estos llamados a la oración y el ayuno una forma de expiación colectiva, que difunde entre la población un sentimiento difuso de culpa y responsabilidad colectiva ante lo que puede aparecer como un castigo divino. Lo anterior tiene como consecuencia una disolución de la responsabilidad de los gobernantes, que

\footnotetext{
36 Redacción, "No mentir, no robar y no traicionar ayuda mucho para que no dé el coronavirus': AMLO", Animal Político, 4 de junio de 2020, disponible en: https://wrere.ani malpolitico.com/2020/06/amlo-no-mentir-robar-traicionar-ayuda-contra-covid/, consultado el $10 \mathrm{de}$ agosto de 2020.

37 Véase, por ejemplo, Blancarte, Roberto, "Un decálogo inmoral", Milenio, 16 abril 2020, disponible en: https://wrwwemilenio.com/opinion/roberto-blancarte/perdon-pero/un-decalogoinmoral, consultado el 11 de agosto de 2020.

38 Gutiérrez-Martínez, Daniel, "Max Weber: las relaciones sociológicas con el pluralismo cultural”, Estudios Sociológicos, núm. 72, vol. XXIV, septiembre-diciembre, 2006, p. 713, disponible en: file:///Users/pcapde/Downloads/Dialnet-MaxWeber-6164246\%20(1).pdf.
} 
Este libro forma parte del acervo de la Biblioteca Jurídica Virtual del Instituto de Investigaciones Jurídicas de la UNAM

entregan el destino de la nación entre las manos de Dios y se deslizan de rendir cuenta respecto a la gestión de la pandemia. La religión es utilizada a fines instrumentales para fortalecer la unión nacional y desalentar la crítica, presentada como factor de división.

iii. Algunos observadores han externado en medios de comunicación ${ }^{39}$ que el llamado a los cielos por parte de algunos dirigentes latinoamericanos ha de leerse como una confesión de impotencia de los Estados en el manejo de la crisis sanitaria, en el marco de escenarios nacionales calamitosos, caracterizados por sistemas de salud insuficientes e ineficientes. $\mathrm{Al}$ respecto, el especialista mexicano en religiones, Bernardo Barranco, apuntó en La fornada:

Pienso que la región latinoamericana está rebasada con un aparato de salud abandonado. Hay incapacidad de los estados para dar respuestas ante la crisis. Recurren al pensamiento mágico como consuelo ante la incapacidad de atender la urgencia sanitaria. Los gobiernos utilizan el universo simbólico de lo religioso como recurso manipulador apelando la resistencia cultural de la población pobre, excluida de los servicios inexistentes del Estado. ${ }^{40}$

iv. Como ya se mencionó, la activación de la narrativa religiosa desde el Estado vulnera el principio de laicidad, el cual es sacrificado en beneficio de los sentimientos religiosos de la población y del discurso de la fe, esperanza y redención en tiempo de crisis. En algunos países formalmente laicos, como Uruguay y Ecuador, los presidentes expresaron que ante la situación no podían excluirse ningún tipo de ayuda, incluso la religiosa, dando paso a una especie de excepcionalidad religiosa en contextos políticos seculares.

\section{La mesianización de los liderazgos regionales}

De forma paralela a la exacerbación del discurso religioso en la esfera política, asistimos también a la consolidación de procesos políticos carismáticos. En su clásico ensayo "La política como vocación" (1919) Max Weber

39 Véase, por ejemplo, EFE, "La fe contra el virus, la otra receta latinoamericana frente a la pandemia", Agencia EFE, Bogotá, 28 de abril de 2020, disponible en: https:// wrwwefe.com/efe/america/sociedad/la-fe-contra-el-virus-otra-receta-latinoamericana-frente-a-pandemia/20000013-4233497, consultado el 20 de agosto de 2020.

40 Barranco, Bernardo, "Jefes de Estado recurren a Dios para enfrentar el Covid-19", La Fornada, México, 10 de junio de 2020, disponible en: https://wrwr.jornada.com. $m x / 2020 / 06 / 10 /$ opinion/018a2pol, consultado el 14 de agosto de 2020. 
Este libro forma parte del acervo de la Biblioteca Jurídica Virtual del Instituto de Investigaciones Jurídicas de la UNAM

identifica tres tipos de legitimidad política: la legitimidad tradicional, del "eterno ayer"; la del carisma, basada en la autoridad de la gracia, y finalmente la racional-legal, característica de los Estados modernos. ${ }^{41}$ Respecto a la segunda, hace énfasis en sus relaciones con lo religioso, al acercar la figura del profeta con los grandes demagogos, los gobernantes plebiscitarios y los jefes de los partidos políticos. La crisis de la COVID-19 hizo más estridente este fenómeno en México y Brasil, donde los presidentes Andrés Manuel López Obrador y Jair Bolsonaro aprovecharon la coyuntura para fortalecer el carácter mesiánico de sus liderazgos.

En México, la estrategia del presidente ha sido minimizar la situación sanitaria y negarse a modificar las condiciones normales del ejercicio del poder. En estas circunstancias, su negativa a usar cubrebocas y a someterse a detección de temperatura corporal no es fortuita, puesto se puede leer a la vez como oposición a cualquier símbolo que enfatice la gravedad de la crisis y como consolidación de su imagen de líder inmune al virus, debido a su fortaleza moral. A mediados del mes de junio, presentó a la ciudadanía un "Decálogo para salir del coronavirus y enfrentar la nueva realidad", documento en el cual recomienda a la población actuar con optimismo, dar la espalda al egoísmo y al individualismo, no dejarse envolver por lo material, alimentarse bien, eliminar las actitudes racistas, clasistas, sexistas y discriminatorias, y last but not least:

10. Tengas o no una religión, seas creyente o no, busca un camino de espiritualidad, un ideal, una utopía, un sueño, un propósito en la vida, algo que te fortalezca en lo interno, en tu autoestima, y que te mantenga activo, entusiasmado, alegre, luchando, trabajando y amando a los seres queridos, al prójimo, a la naturaleza y a la patria. ${ }^{42}$

Retomando las categorías weberianas, la narrativa del presidente desplaza los fundamentos racional-institucionales del poder político, para reforzar un liderazgo de tipo carismático, basado en los dotes excepcionales del líder, designado como el Elegido. Una línea que se hace evidente desde su campaña presidencial en 2018, y que se ha reforzado en el contexto pandémico.

41 Weber, Max, La política como vocación, 1919, disponible en: http://wrerr.copmadrid.es/webcopm/recursos/pol1.pdf.

42 "El Decálogo para salir del coronavirus y enfrentar la nueva realidad", fechado del 12 de julio de 2020, está disponible en el sitio de la Presidencia de la República, en el siguiente vínculo: https://presidente.gob.mx/wp-content/uploads/2020/06/Deca\%CC\%81logo-para-salir-delcoronavirus-y-enfrentar-la-nueva-realidad.pdf, consultado el 13 de agosto de 2020. 
Este libro forma parte del acervo de la Biblioteca Jurídica Virtual del Instituto de Investigaciones Jurídicas de la UNAM

El caso de Jair Bolsonaro es también ilustrativo de este fenómeno. Tras minimizar también el virus en las primeras semanas de la pandemia, y afirmar que "el brasileño no se contagia", ${ }^{43}$ el presidente multiplicó las alusiones religiosas en sus mensajes públicos, siempre respaldado por sus aliados evangélicos. Una de las declaraciones más controversiales y emblemáticas de su gestión de la crisis ha sido la siguiente. Interrogado por periodistas respecto al incremento de fallecidos en el país a finales del mes de abril, el presidente contestó: "Lo lamento. ¿Qué quieres que haga? [...] Soy Mesías, pero no hago milagros", refiriéndose a su segundo nombre, Messias. ${ }^{44}$ En una misma línea discursiva, e insistiendo en la necesidad de mantener activa la economía del país, señaló: "Tenemos que trabajar. Hay muertes, pero eso depende de Dios, no podemos parar". ${ }^{45}$ Tras la destitución de dos ministros de salud por divergencias respecto a la gestión de la pandemia ${ }^{46}$ el presidente nombró en junio de 2020 a un militar, alejando definitivamente los enfoques científicos de la gestión de la pandemia, en aras de un manejo autoritario de la misma. ${ }^{47}$

Tanto en México como en Brasil, el proceso mesianización de los estilos de gobernabilidad es palpable. En ambos casos, destacan las posturas que minimizaron la pandemia, desmeritan el discurso científico y ostentan al líder como inmune a la pandemia. ${ }^{48}$ Ambos mandatarios fueron reacios a

43 Europa Press, "Bolsonaro dijo que el brasileño «no se contagia» de coronavirus porque «bucea en alcantarillas y no le pasa nada»", Infobae, América Latina, 26 de marzo de 2020, disponible en: https://wrere.infobae.com/america/america-latina/2020/03/27/bolsonarodijo-que-el-brasileno-no-se-contagia-de-coronavirus-porque-bucea-en-alcantarillas-y-no-le-pasa-nada/, consultado el 14 de agosto de 2020.

44 Alessi, Gil y Rossi, Marina, "Brasil registra su mayor número de muertos en un día y Bolsonaro reta: “¿Y qué?»”, El País, Sociedad, 29 de abril de 2020, disponible en: https:// elpais.com/sociedad/2020-04-29/brasil-registra-su-mayor-numero-de-muertos-en-un-dia-y-bolsonaroreta-y-que.html?utm_source $=$ FacebookEssm $=F B \_C M \# E$ chobox $=1588149808$, consultado el 14 de agosto de 2020.

45 Reuters, "«Hay muertes, pero eso depende de Dios, no podemos parar»: Bolsonaro", La fornada, 29 de marzo de 2020, disponible en: https://wrere.jornada.com.mx/ultimas/mundo/ 2020/03/29/de-visita-en-mercado-bolsonaro-dice-que-201 cbrasil-no-puede-parar201d-3662.html, consultado el 17 de agosto de 2020.

46 Galarraga Cortázar, Naiara, "Bolsonaro destituye a ministro de salud en plena crisis del coronavirus", El Pais, 16 abril 2020, disponible en: https://elpais.com/internacional/2020-04-16/el-ministro-de-salud-de-brasil-afirma-que-el-presidente-bolsonaro-lo-ha-destituido. html, consultado el 14 agosto 2020.

47 Jucá, Beatriz, "Bolsonaro militariza la sanidad y desplaza a los técnicos de la gestión de la pandemia", El País, 14 de julio de 2020, disponible en: https://elpais.com/internacional/2020-07-14/bolsonaro-militariza-la-sanidad-y-desplaza-a-los-tecnicos-de-la-gestion-de-lapandemia.html, consultado el 17 de agosto de 2020.

$48 \mathrm{Al}$ respecto, es altamente probable que el liderazgo Bolsonaro salga fortalecido tras su contagio y recuperación de la COVID-19. 
Este libro forma parte del acervo de la Biblioteca Jurídica Virtual del Instituto de Investigaciones Jurídicas de la UNAM

limitar sus apariciones públicas, incluso en eventos multitudinarios, ingrediente útil a su estilo de gobierno. En ambos casos también, las referencias a la espiritualidad, la protección y la curación son evidentes.

Ahora bien, si en un primer momento la cuestión de las cuarentenas obligatorias fue colocada el centro del debate político y de la polarización entre diferentes estilos de gobierno, la discusión se desplazó, a la hora en que escribimos estas líneas, a la cuestión de la utilización de los cubrebocas como medida preventiva del SARS-CoV-2. Como mencionamos, el presidente López Obrador, a contracorriente del consenso científico internacional prevaleciente, se ha mostrado renuente a utilizar cubrebocas, al considerar que mantener la sana distancia era suficiente. A finales de julio, señaló que no existía evidencia científica que su uso disminuyera los contagios. ${ }^{49}$ Unos días después, reaccionando a la presentación de un amparo por parte del Partido Acción Nacional para obligarlo a utilizar dicho dispositivo, expresó que lo usará cuando no haya corrupción, "para que ya no hable". ${ }^{50}$ En Brasil, el presidente también ha despreciado en varias ocasiones la utilización de mascarillas, llegando a declarar que "es cosa de gays". ${ }^{51}$ Asimismo, vetó parte de una ley sobre el uso de cubrebocas que determinaba su obligatoriedad en lugares cerrados, tales como establecimientos comerciales e industriales, templos y centros de enseñanza, censurando también su distribución gratuita para las poblaciones más vulnerables. ${ }^{52}$ Durante el mes de junio, un juez federal dictaminó que el gobernante tenía que usar una mascarilla en sus apariciones en público, sin embargo, dicha sentencia fue anulada en segunda instancia, al considerar que la decisión era innecesaria, dado que su uso ya era obligatorio. ${ }^{53}$ Cabe mencionar que en la prensa

49 Redacción, "Si uso de cubrebocas ayudara, entonces lo utilizaría, pero no está científicamente demostrado: AMLO", El Financiero, 24 de julio de 2020, disponible en: https://wrere. elfinanciero.com.mx/salud/si-uso-de-cubrebocas-ayudara-entonces-lo-usaria-pero-no-esta-cientificamentedemostrado-amlo, consultado el 13 de agosto de 2020.

50 HM, "Me pondré un cubrebocas cuando no haya corrupción: AMLO", El Universal, 31 de julio de 2020, disponible en: https://wrerceluniversal.com.mx/nacion/amlo-me-pondre-cubrebocas-cuando-no-haya-corrupcion, consultado el 14 de agosto de 2020.

51 La Razón Online, "Usar cubrebocas «es cosas de gays»: Bolsonaro", La Razón, 9 de julio de 2020, disponible en: https://wrwrerazon.com.mx/mundo/usar-cubrebocas-es-cosa-de-gaysbolsonaro-396960, consultado el 14 de agosto de 2020.

52 EFE, "Jair Bolsonaro veta el uso obligatorio de mascarillas en los comercios, templos y escuelas de Brasil", El Mundo, 3 de julio de 2020, disponible en: https://wrercelmundo.es/inte rnacional/2020/07/03/5eff4e4efdddff95818b4751.html, consultado el 14 de agosto de 2020.

53 AFP, "Juez anula fallo que obligaba a Bolsonaro a usar cubrebocas", Informador.mx, 30 de junio de 2020, disponible en: https://wwere.informador.mx/internacional/fueza-anula-fallo-queobligaba-a-Bolsonaro-a-usar-cubrebocas-20200630-0139.html, consultado el 20 de agosto de 2020. 
Este libro forma parte del acervo de la Biblioteca Jurídica Virtual del Instituto de Investigaciones Jurídicas de la UNAM

se hizo eco de diferentes apariciones del mandatorio contagiado de COVID-19 sin el uso requerido de la mascarilla, especialmente, con motivo del anuncio de su infección ante los medios de comunicación. ${ }^{54}$ Así las cosas, aparece claramente que el uso del cubrebocas se ha politizado. Al respecto, Diego Fonseca nota que:

Trump, AMLO, Bolsonaro, Johnson, entre otros, son líderes mesiánicos que se vanaglorian de ir a contracorriente. Son personalistas mágicos: la realidad debe ajustarse a su deseo, y su deseo a menudo dista de ser razonable. Tienen visiones invariables del mundo, se han educado en la oposición permanente, hijos de una comprensión del poder vetusta, donde el jefe no puede ser vulnerable. Para un macho, protegerse es de blandengues. ${ }^{55}$

En los inicios de la crisis sanitaria, Júlia Aslina subrayaba la escenificación de las posturas negacionistas de Andrés Manuel López Obrador y Bolsonaro, traducidas en baños de masas, besos y abrazos como aspectos claves de una comunicación que se apoya en el campo de las emociones. ${ }^{56}$ Sin lugar a duda, el rechazo a utilizar el cubrebocas se inscribe en un mismo registro narrativo, el cual insiste en el líder salvador, que da la cara a pesar de los peligros y de los adversarios políticos.

\section{BIOÉTICA, GIENCIA Y GULTURA LAICA EN AMÉRICA LATINA EN CONTEXTO DE PANDEMIA}

Ciencia y religión no necesariamente entran en conflicto en el marco de la contingencia sanitaria generada por la COVID-19. Para los creyentes, el elemento religioso resulta sin duda fundamental para encarar la incertidumbre y la pérdida de seres queridos. Por otro lado, la religión no necesariamente

54 Infobae, "Sin mascarilla ni distancia social: las imágenes que muestran como Jair Bolsonaro minimizó los riesgos del coronavirus", Infobae, 13 de agosto de 2020, disponible en: https://wrwe.infobae.com/america/fotos/2020/07/07/sin-mascarilla-ni-distancia-social-lasimagenes-que-muestran-como-jair-bolsonaro-minimizo-los-riesgos-del-coronavirus/, consultado el 14 de agosto de 2020.

55 Fonseca, Diego, "Tápense la boca", The New York Times, Opinión, 6 de agosto de 2020, disponible en: https://wrwenytimes.com/es/2020/08/06/espanol/opinion/cubrebocas-guerra-cultural.html, consultado el 10 de agosto de 2020.

56 Alsina, Júlia, "Bolsonaro, Trump, AMLO y Johnson, el liderazgo negligente”, en Gutiérrez-Rubí, Antoni y Pont Sorribes, Carles (coords.), Comunicación politica en tiempos de coronavirus, Barcelona, Cátedra Ideograma-UPF de Comunicación Política y Democracia, 2020, p. 64, disponible en: https://wrerr.upf.edu/documents/220602201/233560922/Definitiu+ Comunicaci\%C3\%B3n+Coronavirus/1c1d3def-34ae-fe5d-0019-ef40c936b0e3. 
Este libro forma parte del acervo de la Biblioteca Jurídica Virtual del Instituto de Investigaciones Jurídicas de la UNAM

se enfrenta a la ciencia, sino que en muchos casos se presenta como un vector de racionalidad, como lo atestigua el protagonismo de las instituciones religiosas, las cuales, en su gran mayoría, acataron las medidas de suspensión del culto, y llamaron a la feligresía a quedarse en casa y a participar en las ceremonias religiosas vía remota.

La cuestión ha de centrarse, más bien, en la movilización de una bioética laica como eje de gobierno para frenar los contagios y la mortalidad asociada con el SARS-CoV-2. La bioética se presenta como un discurso que moviliza las aportaciones de diferentes disciplinas, tal como las ciencias de la vida, la medicina, la filosofía, el derecho, la sociología, etcétera, para reflexionar en torno a la conducta humana y sus repercusiones en su entorno. Sus aportaciones resultan fundamentales en un contexto de pandemia, especialmente, desde su vertiente social, ${ }^{57}$ al impulsar una reflexión en torno a los aspectos colectivos de la enfermedad y al replantear las responsabilidades del Estado, de las personas y de la sociedad en general frente a una problemática que rebasa por mucho los aspectos individuales de la enfermedad.

Frente a la utilización instrumental de la religión por parte de los líderes latinoamericanos, el enfoque en el carácter laico de la bioética es fundamental, al permitir (re)centar el debate en torno al protagonismo que debe asumir el aparato del Estado respecto a la crisis sanitaria, a partir de la evidencia científica, y desde una perspectiva de salud pública y de derechos humanos. Al respecto, la bioética laica no busca invisibilizar lo religioso o negar su relevancia para los creyentes, sino simplemente considera que los actos de fe corresponden a la esfera privada de las personas y que no pueden constituir el eje de las políticas públicas o de los discursos políticos. ${ }^{58}$ De esta manera, la bioética ha de ser autónoma de las consideraciones religiosas y dogmáticas en general, para poder cumplir con su objetivo que consiste en buscar los elementos de un conocimiento certero basado en el método científico y aportar soluciones aceptables para todos, más allá de las adscripciones particulares. ${ }^{59}$ Así las cosas, se presenta como el vector de una política de salud pública inteligible, transparente, consensuada entre diferentes niveles de gobierno y basada en una pedagogía

57 Vázquez, Rodolfo, "Bioética y derecho. Retos para una agenda de discusión en México", s/r, p. 2, disponible en: https://wrere.uaeh.edu.mx/campus/icsa/noticias/2/docs/2013/2/ bioetica_y_derecho.pdf.

58 Medina Arellano, María de Jesús, "Laicidad y bioética", en Arlettaz, Fernando y Capdevielle, Pauline, Escenarios actuales de la laicidad en América Latina, México, UNAM, Instituto de Investigaciones Jurídicas, 2019, p. 198.

59 Idem. 
Este libro forma parte del acervo de la Biblioteca Jurídica Virtual del Instituto de Investigaciones Jurídicas de la UNAM

científica. Ello no es evidente en un mundo caracterizado por el incremento de los discursos donde la creencia está colocada a un mismo nivel que la evidencia. ${ }^{60}$ En este mundo que algunos califican de postverdad, cualquier opinión, sea o no respaldada por hechos, vale lo mismo que cualquier otra.

El movimiento anticubrebocas es un buen ejemplo de ello. Su rechazo no se limita a los líderes políticos. En diferentes partes del globo, con especial éxito en Estados Unidos y en algunos países de Europa, han surgido grupos organizados que resisten a su obligatoriedad. Si bien los perfiles de los inconformes son diferentes, es posible encontrar ciertas continuidades entre diferentes líneas argumentativas. En primer lugar, no es infrecuente el recurso a teorías conspiracionistas, en particular el tema del control social y la imagen del cubrebocas como mordaza o bozal. Otra veta argumentativa, a veces combinada con la anterior, es la ineficacia e incluso la peligrosidad de las mascarillas, las cuales causarían una falta de oxigenación y un riesgo de hipoxia. También ha aparecido con fuerza, especialmente en Estados Unidos, la temática de la libertad individual, frente a lo que se percibe con colectivismo estatal, e incluso comunismo. Finalmente, la retórica religiosa también ha sido utilizada al considerar que la protección divina hace innecesario dicho dispositivo preventivo, pero también, como en el caso de algunos residentes de Florida, al argumentar que las autoridades quieren "malograr el magnífico sistema respiratorio de Dios". ${ }^{61}$ Un video que circula en las redes sociales, y que muestra la audición de algunos habitantes de dicho estado en el marco de un audiencia de revocación de una decisión de obligatoriedad del cubrebocas, ofrece una buena muestra de los diferentes argumentos utilizados. ${ }^{62}$

Ante este escenario, urge también una mayor difusión de una cultura laica y bioética entre la población. La idea de cultura laica es una expresión atinada por Diego Valadés, que hace referencia a una ciudadanía respetuosa del pluralismo tanto religioso, como filosófico o ético, pero también al desarrollo de un pensamiento crítico y científico. $\mathrm{Al}$ respecto, es patente la grave crisis de fe en la ciencia en América Latina y en el mundo, con un escepticismo cada vez más extendido y el éxito de las teorías conspiracionistas, que mezclan hábilmente realidades y fantasías. México es un buen ejemplo de ello, con una población que se mostró muy escéptica en cuanto

\footnotetext{
60 Alsina, Júlia, op. cit.
}

61 Véase The Telegraph, "Florida residents reject face masks: 'They want to throw God's wonderful breathing system out", YouTube, 25 de junio de 2020, disponible en: https://wrere. youtube.com/watch? $v=$ DaFSH0K4BdQ, consultado el 16 de agosto de 2020.

62 Idem. 
Este libro forma parte del acervo de la Biblioteca Jurídica Virtual del Instituto de Investigaciones Jurídicas de la UNAM

a la existencia misma del virus y reacia a atender las recomendaciones de las autoridades sanitarias. Las agresiones hacia el personal de salud, y la renuencia de la población a llevar a sus enfermos a los centros de la salud pusieron en evidencia la desconfianza hacia la ciencia y las autoridades sanitarias.

Sin lugar a duda, esta situación habla de un fracaso de la educación científica y laica en México, plasmada en el artículo 3o. párr. 2 de la constitución, que enfatiza que "El criterio que orientará a esa educación se basará en los resultados del progreso científico, luchará contra la ignorancia y sus efectos, las servidumbres, los fanatismos y los prejuicios". El fortalecimiento de una cultura laica y científica es indispensable para cerrar el paso a conductas peligrosas que prevalecen en algunos lugares de América Latina. Al respecto, uno de los casos más dramático en los últimos meces fue la administración a al menos 5,000 personas en la región amazónica de Perú, de un antiparásito veterinario presentado a la población como cura al virus. La distribución de dicha "vacuna" fue impulsada por un alcalde local y por algunas misiones evangélicas de la región, que vinculan el nuevo coronavirus con el demonio y el fin del mundo, y ofrecieron esas inyecciones "como una salvación". Algunas de las personas que recibieron la ivermectina veterinaria sufrieron efectos secundarios, en particular, la aceleración del ritmo cardiaco. ${ }^{63}$ En Nicaragua, un pastor evangélico alentó a la población a salir a rezar por la calle, preguntándose públicamente por qué la gente tiene miedo a morir, ya que si se mueren van al cielo y "iEs ganancia!". Recomendó a los fieles el uso de "agua con sal" para prevenir la enfermedad. ${ }^{64}$

\section{CONCLUSiones}

Como se ha argumentado en estas páginas, la utilización del discurso religioso por parte de los líderes latinoamericano para responder a la emergencia sanitaria causada por el SARS-GoV-2 surge en el marco de una cultura política regional caracterizada por una fuerte influencia de la religión y del

63 Fowks, Jacqueline, "Un grupo evangélico peruano inyecta un medicamento veterinario a miles de personas para la covid-19”, El Pais, 19 de junio de 2020, disponible en: https:// elpais.com/sociedad/2020-06-19/un-grupo-evangelico-peruano-inyecta-un-medicamento-veterinario-amiles-de-personas.html, consultado el 14 de agosto de 2020.

64 Vázquez, Vladimir, "Evangélicos reabrirán templos pese a pandemia que ha sido fatal para docenas de sus pastores", Confidencial, 13 de julio de 2020, https://confidencial.com.ni/ evangelicos-reabriran-templos-pese-a-pandemia-que-ha-sido-fatal-para-decenas-de-sus-pastores/, consultado el 15 de agosto de 2020. 
Este libro forma parte del acervo de la Biblioteca Jurídica Virtual del Instituto de Investigaciones Jurídicas de la UNAM

populismo como estrategia de gobierno. Sin embargo, no es casual la exacerbación de las narrativas religiosas en el marco de Estados que no supieron, en las primeras semanas de la crisis, responder de manera ordenada e institucional a los desafíos planteados por la pandemia, y que voltearon hacia los cielos en búsqueda de una intervención divina. La movilización de este discurso político permite una dilución de la responsabilidad de los gobernantes, y una evasión de la rendición de cuentas ante el aumento de los contagios, la saturación de los hospitales, y el incremento de muertes. También, el contexto pandémico ha sido utilizado por diferentes mandatarios para fortalecer una legitimidad política de tipo carismática o mesiánica, que encuentra un terreno propicio a su desarrollo en momentos de incertidumbre y de fragilidad institucional.

La utilización instrumental de la religión para fortalecer los liderazgos regionales genera riesgos a nivel sanitario, pues no permite capacitar y empoderar las ciudadanías en la lucha contra el virus. Pero también tiene como posibles peligros el fortalecimiento de los gobiernos personales, el dogmatismo de los dirigentes y la concentración del poder. Habrá que recordar que el principio de laicidad no es un capricho, sino que permite asegurar las condiciones del desarrollo de un pensamiento crítico, científico, que constituye hoy en día nuestra mejor herramienta para frenar la pandemia. 